\title{
Knowledge Management Practices in Pakistan's Telecom Services Sector
}

\section{Danial Hassan*}

\begin{abstract}
Employee turnover has become a serious problem in knowledge-intensive industries such as telecommunications, where the resulting knowledge loss affects process safety and quality. This study examines knowledge management practices in Pakistan's telecom sector and argues that the impact of knowledge loss could be mitigated through knowledge management. Based on a structured questionnaire administered online to a sample of telecom operators in Pakistan, the results indicate the absence of knowledge management as a strategic response to knowledge loss. Nonetheless, the presence of a young, educated workforce, a strong cooperative culture, and sound ICT provision could be leveraged to build successful knowledge management systems in this sector.
\end{abstract}

Keywords: employee turnover, knowledge loss, telecommunications, Pakistan, knowledge management.

JEL classification: M10, M14, M19.

\section{Introduction}

Employee turnover is associated with the loss of knowledge, which, in turn, affects process safety and quality when errors are perpetuated. To prevent this, a system is needed to accumulate and store knowledge as it develops so that, whenever needed, other employees can easily access it and help reduce process errors (Chosnek, 2010). The retention of technically skilled labor is a serious problem in Pakistan, especially in the information technology (IT) sector where technological changes are rapid and "brain drain" is widespread (Pakistan, Ministry of Science and Technology, 2000).

The telecommunications sector was liberalized in 2003 to reduce the gaps in access to technology among different sections of society. To some extent, this policy followed the vision of the former secretary general of the

\footnotetext{
* Department of Science and Technology Studies, Faculty of Science, University of Malaya (email: de.danial@yahoo.com).
} 
United Nations, Kofi Annan, who at Telecom '99 had observed: "People lack many things: jobs, shelter, food, healthcare, and drinkable water. Today, being cut off from basic telecommunication services is a hardship almost as acute as these other deprivations, and may indeed reduce the chances of finding remedies to them." Indeed, in Pakistan it is common to see a poor man (who may not have access to basic health services or drinkable water) driving a donkey cart while speaking into his Nokia handset (BBC, 1999).

Notwithstanding the rapid growth of the country's telecom industry (see International Telecommunication Union, 2006), the literature has shown that employee turnover remains a key concern (see Shoaib, Noor, Tirmizi, \& Bashir, 2009; Rana, Salaria, Herani, \& Amin, 2009). Turnover is especially serious in knowledge-intensive industries such as telecom services (Chase, 1997), where companies stand to lose not only their employees, but also the knowledge they have accumulated during their working years (see Scalzo, 2006; Massingham, 2008).

Several studies suggest that knowledge management $(\mathrm{KM})$ is a viable solution to the problem of knowledge loss (see Natarajan \& Shekhar, 2001; Tiwana, 2002; Peters, 2007; Saunders, 2007). This study aims to examine knowledge loss and KM practices in Pakistan's telecom sector. In so doing, we follow Smith (1989) and Weiss (1989), who note that the first step in managerial problem solving and policy formulation is to identify the problem. In this context, Tiwana's (2002) implementation strategy for KM entails "analyzing and accounting for what is already in place" in order to "identify critical gaps in the existing infrastructure" and thereby "build on what already exists."

Given the dearth of literature on the organizational dynamics of telecom service providers in Pakistan, especially in the context of KM, this study provides a useful reference for planning and discussion among policymakers and regulators.

\section{A Review of the KM Literature}

Lank (1997) argues that several factors make it necessary for firms to manage their knowledge and retain their expertise as important assets in relation to their competitive advantage. These include the speed of change in and intensity of competitive environments, the boom in service-based industries, and the development of IT. 
Knowledge and expertise are now seen as the most valuable asset of firms competing globally (Demarest, 1997). The effective management and coordination of knowledge is thus essential (Wiig, 1994). Organizations must create, capture, harvest, share, and apply their knowledge and expertise to remain competitive (Zack, 1999). Prusak (1996) suggests that the only factor that gives a firm a competitive edge and is sustainable is what the firm knows, how it leverages what it knows, and how fast it can acquire new knowledge.

$\mathrm{KM}$ comprises a number of key aspects. One of these is the process of capturing an organization's collective knowledge-whether it is encoded in electronic form or hard copy or resides in the organization's workers-and channeling it to wherever it can help produce the largest return (Hibbard, 1997). Another aspect is the orderly and explicit building, renewal, and application of knowledge to maximize an enterprise's knowledge-related effectiveness and returns (Wiig, 1997). Finally, KM also implies ensuring that the right knowledge reaches the right people at the right time, enabling them to make better decisions (Petrash, 1996).

As with any other management discipline, $\mathrm{KM}$ has attracted criticism (see Mårtensson, 2000; Wilson, 2002), especially with regard to a conceptual understanding of knowledge, the lack of a uniform definition, and tools for measuring knowledge. In the context of this study, we clearly assume that engineers working on telecom networks acquire new and explicit knowledge, which, if recorded and shared, could help ensure smoother network operations. Since such knowledge is usually stored in the form of personal notes, it is lost to the firm when the employee leaves.

\section{Research Methodology and Dataset}

A 46-item structured questionnaire was developed to collect data for this study. The survey was adapted from Kosilov's (2008) study of KM self-assessment and comprises seven sections, each of which is designed to measure the strength of a functional category related to KM (Table 1). 


\section{Table 1: Functional categories of survey}

\begin{tabular}{lc}
\hline Functional category & Questions \\
\hline Training and human performance improvement & $5-11$ \\
Methods, procedures, and documentation & $12-17$ \\
KM technology & $18-23$ \\
Approaches to capturing knowledge & $24-27$ \\
Management for KM & $28-32$ \\
Human resource planning & $33-37$ \\
Culture of organization & $38-46$ \\
\hline
\end{tabular}

Source: Adapted from Kosilov (2008).

Questions 1-4 refer to demographic information such as age, education, experience, and employer. Questions 5-46 are measured on a five-point Likert scale where 2 = "strongly agree," $1=$ "agree," $0=$ "neutral," $-1=$ "disagree," and $-2=$ "strongly disagree." The data are presented in the form of percentage distributions with simple averages for individual items (see McCall, 2001, for an analysis of the Likert scale).

The survey was administered online to members of the Zumbeel ${ }^{1}$ Yahoo group, based on convenient sampling. Only the responses received from those telecom engineers currently working in Pakistan were selected. In all, 437 engineers responded, of which 97 responses were discarded because the respondents were not Pakistan-based; 340 responses were thus selected for analysis.

Table 2 presents demographic information on the survey participants. More than half the respondents are aged 25-29 (54 percent), which is as expected, given the age of the industry (the telecom sector was liberalized in 2003). The second largest group aged 30-35 comprises mostly people in managerial positions. All the respondents have professional degrees in computer science, telecommunication engineering, or electrical engineering; only 16 percent have postgraduate degrees. The survey represents all the major telecom service providers. The majority of respondents have more than one year's experience; only 6 percent have less than a year's experience.

\footnotetext{
${ }^{1}$ Zumbeel (www.zumbeel.org) was initially set up as a Yahoo group in 2000 and is now the largest information portal of the telecom industry in Pakistan. Approximately 14,000 website members are of Pakistani origin.
} 
Table 2: Demography of survey respondents

\begin{tabular}{lllrllll}
\hline Age & \% & Education & $\%$ & Organization & & Experience & $\%$ \\
\hline $20-24$ & 9 & Undergraduate & 84 & PTCL & 59 & $<1$ year & 6 \\
$25-29$ & 54 & Postgraduate & 16 & Mobilink & 70 & $1-3$ years & 28 \\
$30-35$ & 28 & & & Ufone & 42 & $4-7$ years & 41 \\
$>35$ & 4 & & & CMPak & 22 & $8-11$ years & 17 \\
& & & Telenor & 53 & $\geq 12$ years & 8 \\
& & & Warid & 46 & & \\
& & & TeleCard & 29 & & \\
& & Worldcall & 19 & & \\
& & & Total & 340 & & \\
\hline
\end{tabular}

\section{KM Practices in Pakistan}

Figure 1 presents the results for the training and human performance functional category. As can be seen, most respondents agree that the training they received on recruitment provided relevant knowledge, although the evidence for systematic training programs is weak, with an average of 0.14 (Table 3, Q5). This is consistent with Muhammad, Aurangzeb, and Tarique (2009) who find that telecom companies in Pakistan appear reluctant to train new recruits on the grounds that it incurs additional expense. 
Figure 1: Results for training and human performance

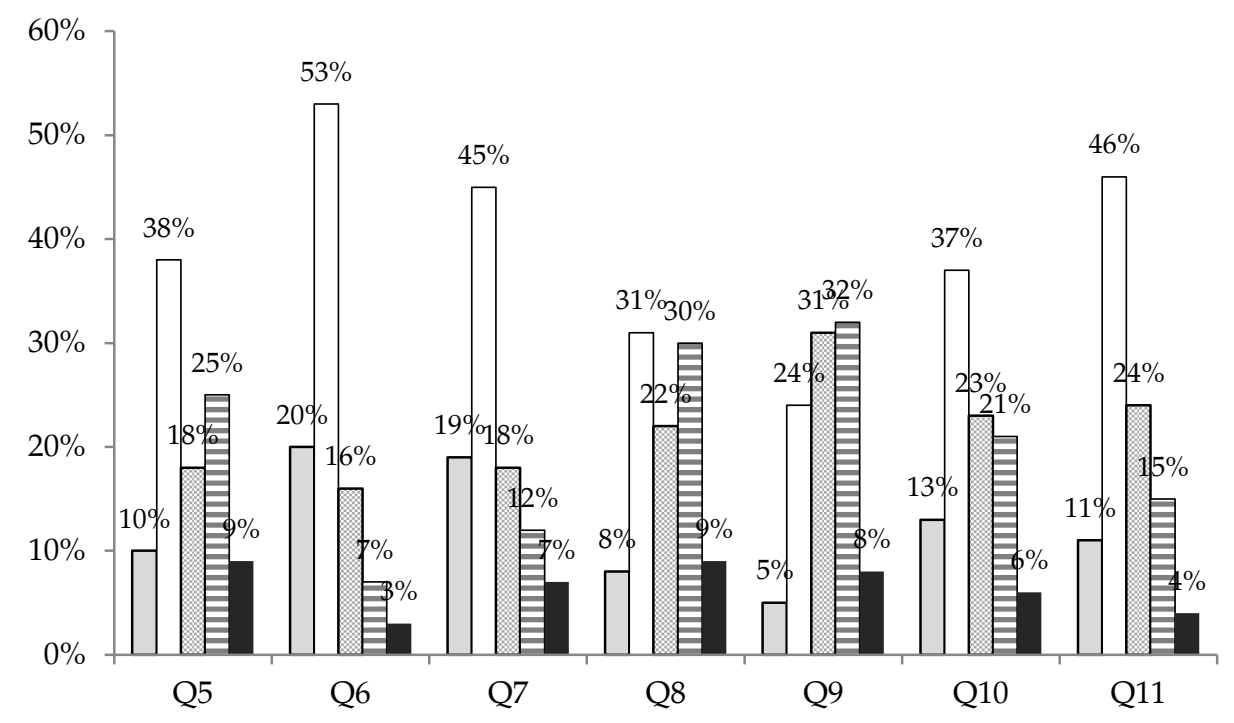

$\square$ Strongly agree $\square$ Agree $\square$ Neutral/undecided $\boxminus$ Disagree $\square$ Strongly disagree

Q5: Systematic training programs for engineers.

Q6: Training programs provide relevant knowledge.

Q7: Training tools such as simulations, multimedia, etc.

Q8: Competence evaluated regularly.

Q9: Refresher courses carried out to maintain competence.

Q10: Coaching and mentoring approaches to support knowledge sharing.

Q11: Training provides sufficient knowledge for job performance.

Regular refresher training programs and competence evaluation score the lowest in this category with an average of -0.14 and -0.01 (Table 3, Q9 and Q8), respectively. Competence evaluation is key to increasing employees' productivity so that training programs can be tailored accordingly (Dransfield, 2000). The lack of competence evaluation points to the lack of systematic training programs. Such training is necessary, given that it is rarely provided at colleges and universities. While telecom companies may have no choice but to provide some form of training, the emphasis appears to be on unsystematic, on-the-job training programs.

Telecom operations do not leave much room for trial and error, making it important to train engineers to identify and locate problems and determine and apply the correct solutions. Solutions based on trial and 
error are likely to cause loss of revenue and reputation (see Bigelow, 2002, for a discussion of operational excellence).

Table 3: Average scores for survey questions 5-46

\begin{tabular}{lccccccc}
\hline Q. & Average & Q. & Average & Q. & Average & Q. & Average \\
\hline 5 & 0.147727273 & 16 & 0.818181818 & 27 & 0.068181818 & 38 & 0.329545455 \\
6 & 0.806818182 & 17 & -0.215909091 & 28 & 0.238636364 & 39 & -0.090909091 \\
7 & 0.568181818 & 18 & 0.568181818 & 29 & 0.238636364 & 40 & -0.204545455 \\
8 & -0.011363636 & 19 & 1.113636364 & 30 & 0.079545455 & 41 & 0.215909091 \\
9 & -0.147727273 & 20 & 0.50000000 & 31 & 0.000000000 & 42 & 0.488636364 \\
10 & 0.272727273 & 21 & 0.818181818 & 32 & 0.056818182 & 43 & 0.329545455 \\
11 & 0.465909091 & 22 & 0.647727273 & 33 & -0.181818182 & 44 & 0.102272727 \\
12 & 0.443181818 & 23 & 0.511363636 & 34 & -0.295454545 & 45 & 0.420454545 \\
13 & 0.420454545 & 24 & 0.000000000 & 35 & -0.215909091 & 46 & 0.284090909 \\
14 & 0.238636364 & 25 & -0.022727273 & 36 & -0.375000000 & & \\
15 & 0.159090909 & 26 & 0.000000000 & 37 & -0.215909091 & & \\
\hline
\end{tabular}

Source: Author's calculations.

Figure 2 shows that nearly 70 percent of the respondents agree that engineers are capable of solving problems and creating new knowledge-a finding that is consistent with studies that identify the presence of a talented workforce in Pakistan (see Aziz, Khan, \& Aziz, 2008). Network operations in telecom companies entail engineers working in shifts over 24 hours, seven days a week. Any change or problem in the network must be communicated to those engineers who are to work the next shift, for which purpose documentation is necessary. This can take the form of verbal communication, emails, and shift rosters.

Our results indicate that documentation and learning-by-doing are formal activities within network operations. However, there is little job rotation for the purpose of sharing network knowledge among different functional departments. Job rotation helps create informal networks within the organization, which facilitates the flow of information.

Feedback concerning employees' experience is, however, recorded and applied to ensure smoother network operations. This is important, given the sensitivity of telecom network operations, the fact that there is no room for error, and that customers are able to maintain continuous contact with their service providers. Unlike other industrial operations where 
customers are not always in contact with the company and machines can be stopped to resolve errors, in telecom operations stopping a machine would mean halting the service.

Figure 2: Results for methods, procedures, and document processes

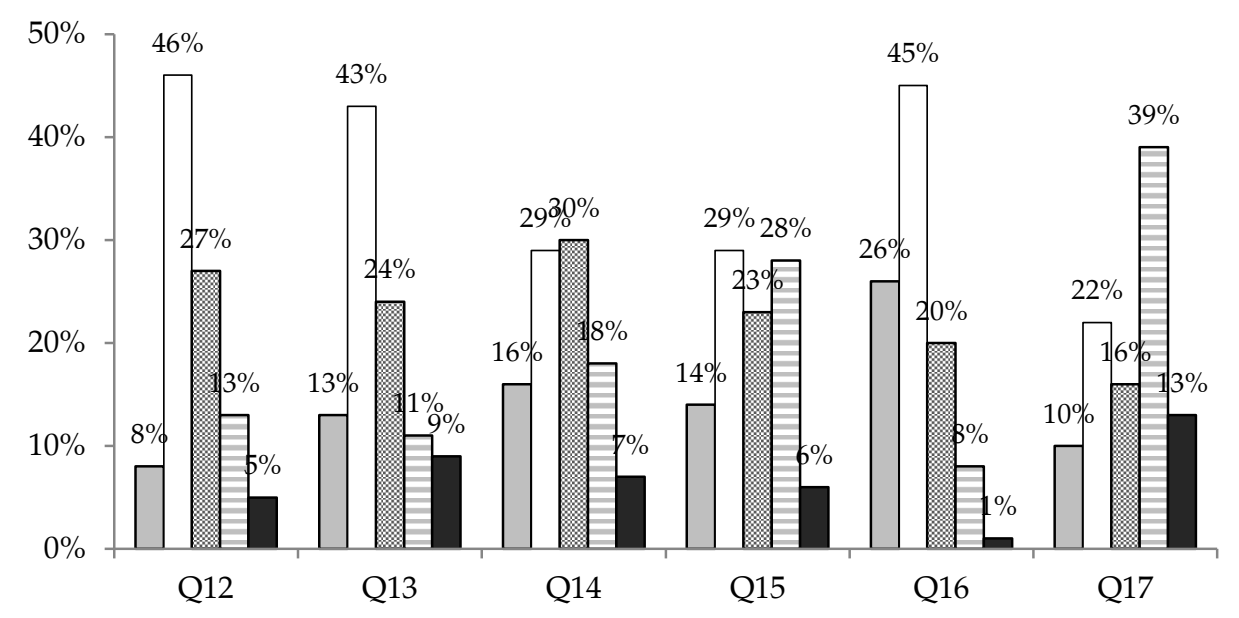

$\square$ Strongly agree $\square$ Agree $\square$ Neutral/undecided $\square$ Disagree $\square$ Strongly disagree

Q12: Comprehensive methodology for learning from experience.

Q13: Feedback (internal and external) for operational experience.

Q14: Formal process for transferring best practices.

Q15: Planning activities to be effectively retrieved, shared, and utilized.

Q16: Engineers capable of creating new knowledge to resolve problems on their own.

Q17: Job rotation practiced, e.g., between RF and BSS, and switching to learn from each other.

There is only weak evidence of any formal activity geared toward a KM-centric strategy. Q15 and Q14 in Table 3 indicate that the majority of respondents are either neutral or disagree as to whether formal processes are in place to transfer best practices. Network operations departments are usually managed by engineers who are more likely to adopt a scientific approach to management. The nature of operations also demands that certain practices exist by default, such as documentation and feedback. If formalized, these attributes could help create a better work environment and contribute to operational excellence.

Information and communication technologies (ICT) are a vital ingredient of successful KM systems (see Milton, Shadbolt, Cottam, \& Hamersley, 1999; Sher \& Lee, 2004). ICT hastens the creation of knowledge 
and enables quicker delivery to remote places. Figure 3 presents the results for the functional category of technology. This category scores the highest, with an overall average score of 0.69 (Q18-Q23, Table 4).

Figure 3: Results for technology

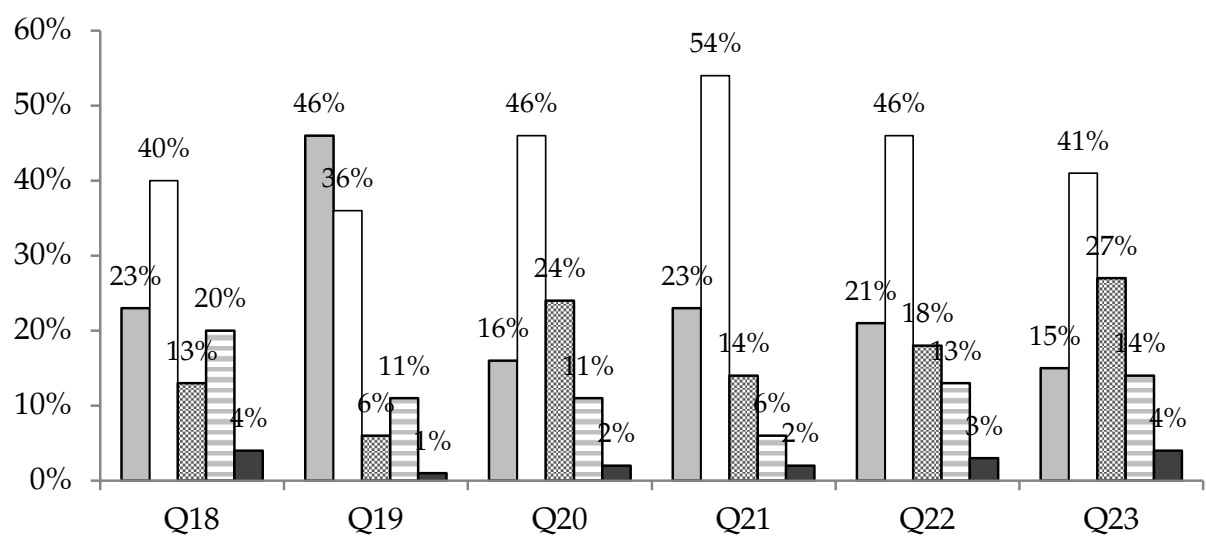

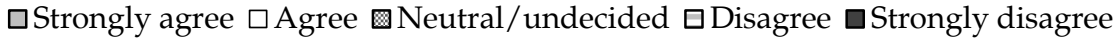

Q18: Portals/Internet, knowledge search engines, knowledge databases, etc.

Q19: Adequate provision of laptops/computers and Internet to engineers.

Q20: Technology creates an institutional memory, accessible to all.

Q21: Technology links all members of the enterprise.

Q22: Information systems are realtime, integrated, and smart.

Q23: Technology is rapidly being put in the hands of employees.

The results reflect the fact that telecom companies provide ICT services and must, therefore, be technologically well equipped. Bloodgood and Salisbury (2001) observe that IT is associated with two capabilities: the codification of knowledge (e.g., databases) and the creation of networks. Most respondents agree that technology creates an "institutional memory" (Q20, Figure 3) that is universally accessible. It also links the members of an organization, thus creating networks for the flow of knowledge and information. Creating an institutional memory is at the core of KM systems (see van Heijst, van der Spek, \& Kruizinga, 1997; Dieng et al., 1999), almost all of which rely on a database of lessons learned and best practices.

The provision of IT facilities such as laptops/computers and Internet access is deemed satisfactory: these facilities not only improve employees' effectiveness, but they also connect colleagues and track network changes. Telecom services often require engineers to spend considerable time maintaining and monitoring networks; adequate IT 
facilities allow them to remain mobile and work remotely while connected to the network. This makes the company's institutional memory more effective, reduces the time spent on problem solving, and improves employees' quality of life at work.

Table 4: Averages of functional categories

\begin{tabular}{llc}
\hline Average of Q. & \multicolumn{1}{c}{ Functional category } & Overall average \\
\hline Q. 5-11 & Training and human performance & 0.300324675 \\
Q. 12-17 & Methods, procedures, and documentation & 0.310606061 \\
Q. 18-23 & Technology for KM & 0.693181818 \\
Q. 24-27 & Approaches to capturing knowledge & 0.011363636 \\
Q. 28-32 & Management for KM & 0.122727273 \\
Q. 33-37 & Human resource planning & -0.256818182 \\
Q. 38-46 & Culture of organization & 0.208333333 \\
\hline
\end{tabular}

Source: Author's calculations.

A large part of corporate knowledge is stored as either personal knowledge or personal records (Whyte, 1957; Zajonc \& Wolfe, 1966; Sharp \& Lewis, 1993) and may be lost due to employee turnover. This makes it important to identify which employees possess knowledge that is critical to the company (see Klein, 1998, on the importance of intellectual capital; Bontis \& Nikitopoulos, 2002; Johanson, 2005). Q24 and Q25 (Figure 4) were framed to determine how this critical knowledge is identified in the telecom industry. However, the bulk of responses range from "disagree" to "neutral." This implies that respondents failed to understand the questions or were not aware how the management identified critical knowledge or disagreed that sources of critical knowledge were formally identified at all.

When asked if technology creates an institutional memory that is accessible by all (Q20, Figure 3), most respondents agree that it does. Q26 and Q27, however, focus on the effectiveness of this memory, with the results (primarily neutral) suggesting that the practice is largely absent irrespective of the respondents' level. Thus, there is weak evidence for the effectiveness of institutional memory (Q26, Figure 4).

Figure 4 also highlights respondents' conceptual understanding of management strategies: many respondents remain neutral or disagree. This may be because they are unfamiliar with management terminology and strategies, given that (i) only 16 percent have postgraduate degrees and (ii) telecom companies seem reluctant to provide technical training, much less 
in management (Muhammad et al., 2009). This lack of conceptual understanding of management strategies has implications for education policy. Policymakers need to ensure that engineers have access not only to technical expertise and knowledge, but also to adequate knowledge about management principles. Companies also need to provide managementrelated training to facilitate the implementation of KM strategies.

Figure 4: Results for approaches to capturing knowledge

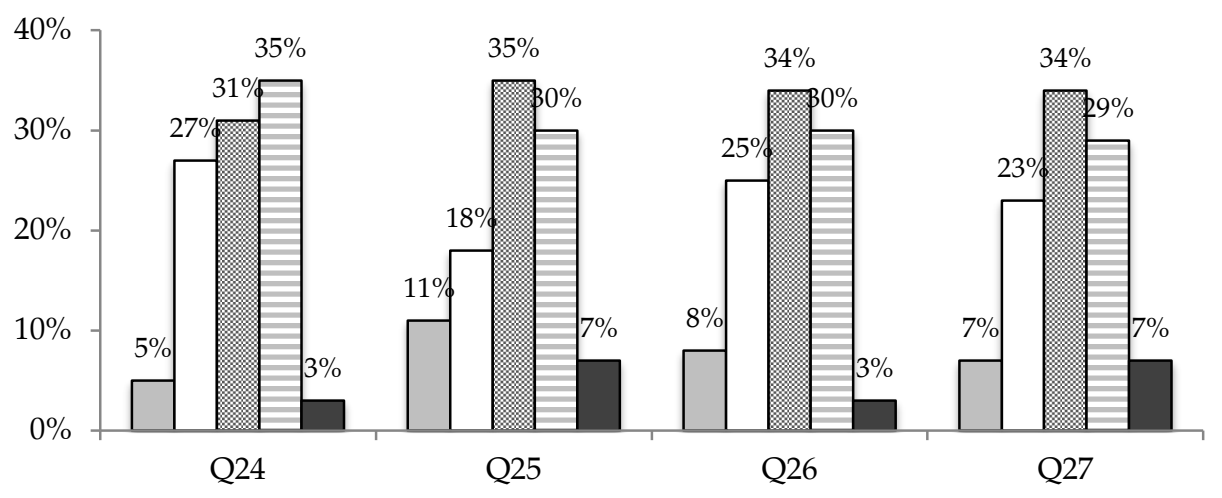

$\square$ Strongly agree $\square$ Agree $⿴$ Neutral/undecided $\square$ Disagree $\square$ Strongly disagree

Q24: Identification of people with critical knowledge.

Q25: Methods to identify people, e.g., elicitation interviews.

Q26: Information is managed to facilitate search and retrieval.

Q27: Processes to leverage captured knowledge.

Awareness of the importance of knowledge is different from building and using knowledge assets. Figure 5 (Q29) shows that telecom companies in Pakistan realize the importance of knowledge, but do not necessarily take steps to create knowledge assets. For example, if employees create knowledge and creating knowledge assets is one of the goals of a company, the achievement of this goal should be rewarded. The results do not, however, reflect a clear industry position with an equal proportion of respondents indicating that they agree and disagree.

Although we have also sorted the survey responses by organization to determine whether a particular company engages in formal knowledge creation, the size of the sample prevents a clear pattern from emerging. Knowledge creation activities appear to vary across teams in the same organization, perhaps because they are planned according to managers' personal preferences. Figure 5 indicates the absence of a conscious effort to turn learning into knowledge assets. 
A company's management plays a key role in every phase of KM from knowledge creation to knowledge sharing (Chong, 2006). Apart from the consensus that management recognizes the importance of knowledge, the survey results do not suggest the presence or practice of formal activities geared toward KM, such as reward systems for knowledge capture. Many respondents remain undecided in this section of the survey, which could indicate the absence of such practices (although not necessarily that the managers concerned are weak).

Figure 5: Results for KM management

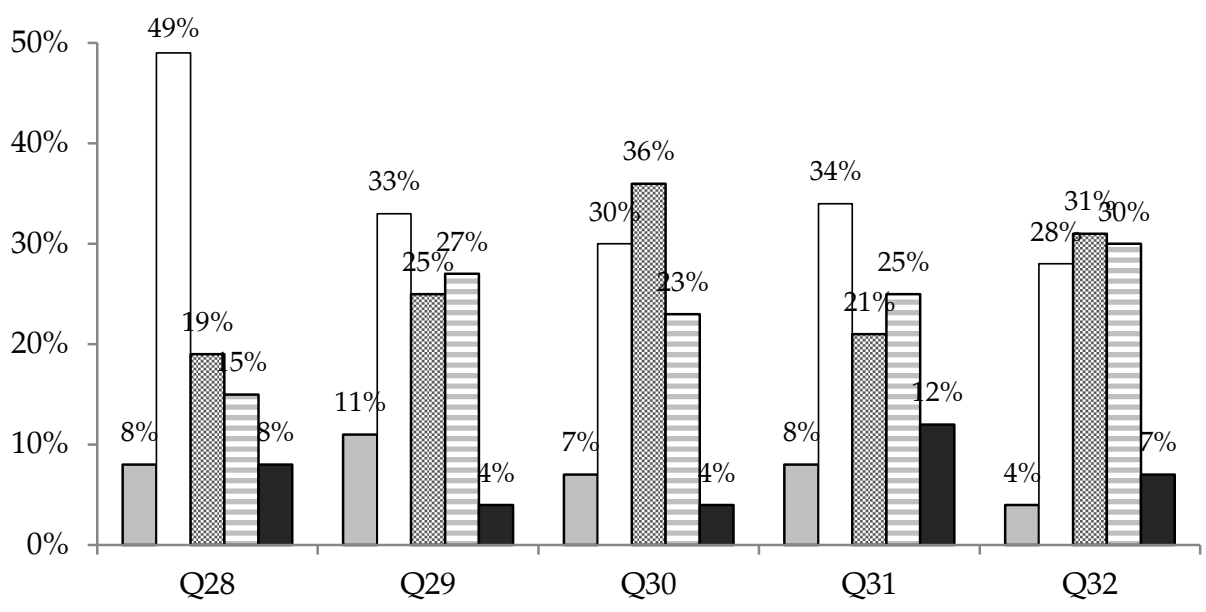

$\square$ Strongly agree $\square$ Agree $⿴$ Neutral/undecided $\boxminus$ Disagree $\square$ Strongly disagree

Q28: Management recognizes the importance of knowledge.

Q29: Learning from activities to build knowledge assets.

Q30: Formal process to transfer best practices.

Q31: Remuneration based on contribution to organizational knowledge.

Q32: Learning as a strategic focus.

Figure 6 presents the results for the functional category of human resource planning and processes. Consistent with previous studies (see Budhwar \& Debrah, 2001), the results indicate poor human resource planning. Given that human resources represent a significant repository of corporate knowledge, both succession planning and risk assessment are important to ensure that critical knowledge is transferred effectively to succeeding employees. As Table 3 (Q34 and Q35) shows, however, both these aspects correspond to weak scores $(-0.29$ and -0.21$)$. 
The poor performance of human resources from a KM perspective might be explained by the difficulty of measuring knowledge assets (Luthy, 1998; Stewart, 1997). As mentioned earlier, there is no universal definition of knowledge or uniform methods for measuring it (Mårtensson, 2000; Wilson, 2002). The results also suggest that many respondents are dissatisfied with the state of human resource planning in their organizations, which does not bode well for implementing successful KM.

Figure 6: Results for HR planning and processes

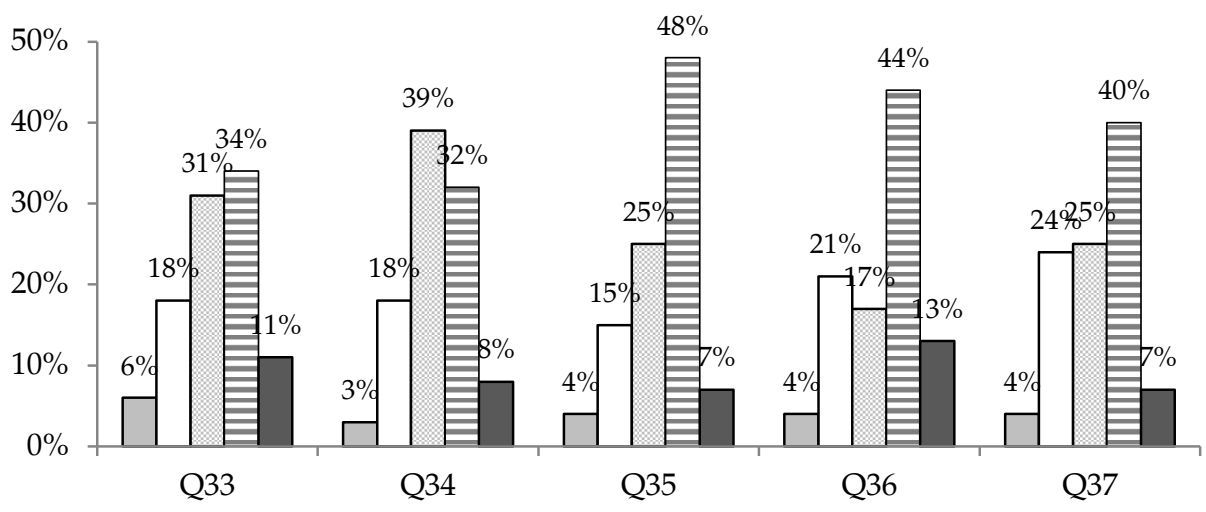

$\square$ Strongly agree $\square$ Agree $\square$ Neutral/undecided $\boxminus$ Disagree $\square$ Strongly disagree

Q33: Comprehensive methodology for workforce planning.

Q34: Effective succession planning program in place.

Q35: Risk assessment (loss of critical knowledge and skills).

Q36: Program to develop new leadership/technical talent.

Q37: Job profiles to assess and monitor skills and competence needs.

The last functional category concerns the culture of the organization: KM projects are liable to fail in the absence of a company culture that facilitates KM (see De Long \& Fahey, 2000). In order to create knowledge, companies need to develop an environment of trust that allows problems and issues to surface and solutions to be generated. Such an environment appears to be lacking (Q39, Figure 7). The adoption of a no-blame approach to reporting incidents/events scores a very low -0.09 , on average. Recognition and reward score -0.20 , on average (Table 3 ). Both these aspects are key components of organizational culture (see Ives, Torrey, \& Gordon, 2002).

Other aspects of culture correspond to moderate scores, such as cooperation among employees and managers' capacity for listening to the 
problems their employees face. Thus, while there is some evidence of organizational culture at the employee level, this needs considerable improvement at the management level.

\section{Figure 7: Results for culture of organization}

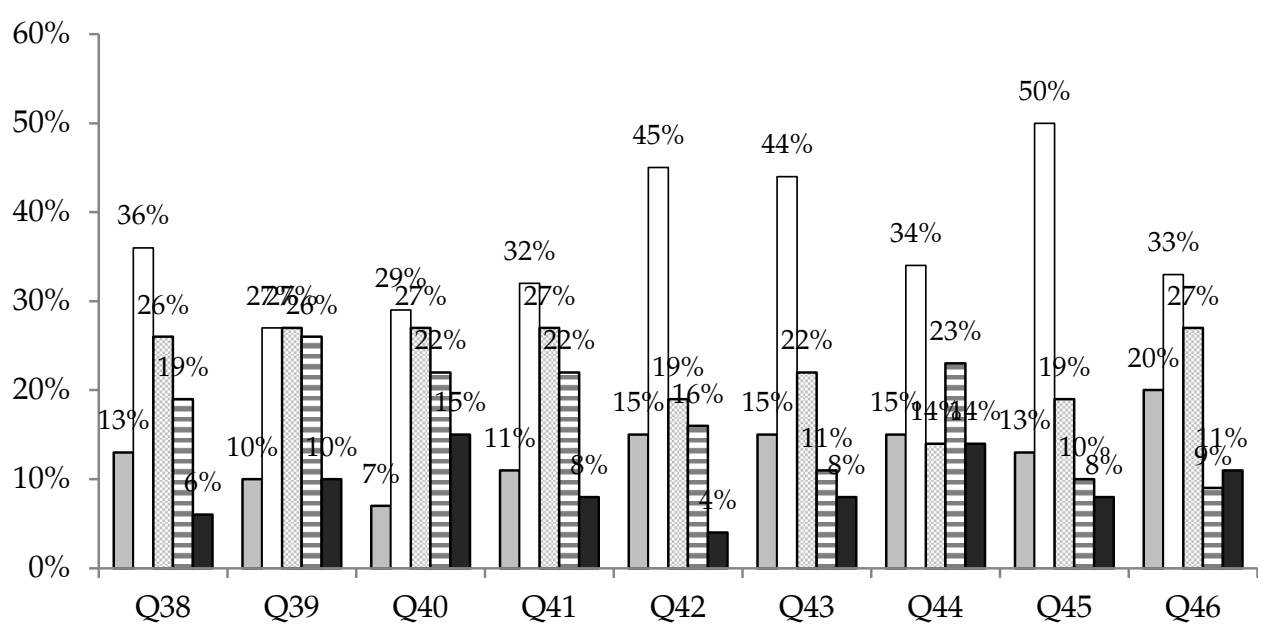

$\square$ Strongly agree $\square$ Agree $\square$ Neutral/undecided $\square$ Disagree $\square$ Strongly disagree

Q38: Organizational culture promotes the sharing and transfer of knowledge.

Q39: Open, no-blame approach to reporting incidents/events.

Q40: Sharing of knowledge in the organization is recognized and rewarded.

Q41: Managers lead by example.

Q42: Managers encourage trust, cooperation, and collaboration.

Q43: Managers listen to the problems faced by engineers.

Q44: Failure is seen as an opportunity to learn.

Q45: Employees are cooperative and helpful.

Q46: Knowledge sharing is seen as a strength and knowledge hoarding as a weakness.

Figure 8 plots the individual average score for each question and represents the industry's KM system. The irregularity of the graph suggests there is no uniform system of KM practices in place, although some aspects may score better than others.

Overall, the survey results reflect the findings of previous studies on the individual functional categories we have examined. This is keeping in mind that very few studies have focused on Pakistan's telecom sector post-liberalization. 
Figure 8: Knowledge management line for telecom sector

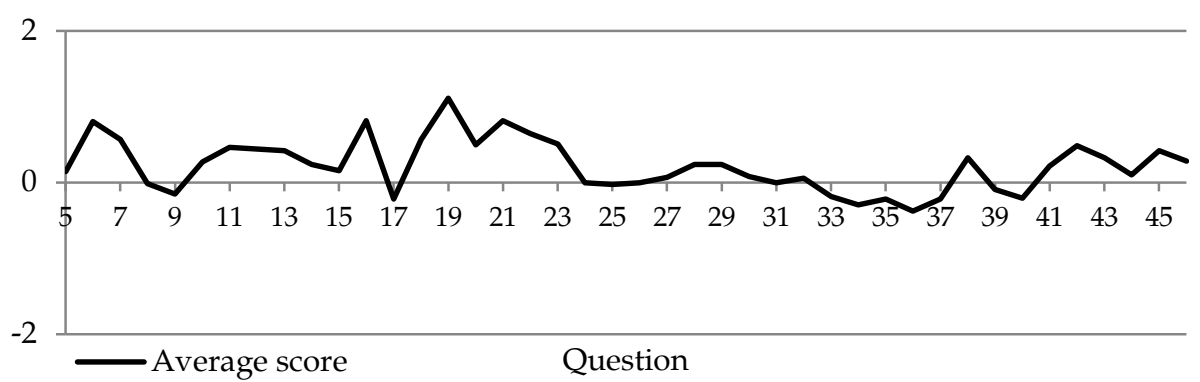

\section{Conclusion and Recommendations}

Based on the results of this survey, there is little evidence that Pakistani telecom service providers have succeeded in leveraging KM practices to compensate for knowledge loss. However, the presence of a young, educated workforce, a positive work culture among engineers, and sufficient technology provision are strong indicators of potential success in the future implementation of KM systems.

One of the aims of this study was to underscore the need for policymakers and regulators in Pakistan to focus on strengthening the sector by expanding their role from conventional regulation to facilitating positive change. Developing an improved telecom infrastructure, for example, is necessary for economic development (Röller \& Waverman, 2001). Business-friendly policies are already in place, as evident from the growth of the sector and the presence of global players such as Orascom, Telenor, Etisalat, and Qatar Telecom. However, the problem of knowledge loss must be resolved, for example, through multi-stakeholder dialogue and corporate training and observation for feedback.

Other areas of related research could include perceptions of KM in the telecom sector, which would lay the groundwork for the implementation of KM systems. Additionally, the study could be extended beyond network operations to analyses of other departments, including human resources, planning, finance, procurement, and management.

While policies adopted by the Pakistan Telecommunication Authority have enabled the expansion of the telecom infrastructure and made it possible for more and more people to afford telecom services, regulators need to improve the quality of services provided. This will mean involving all stakeholders and providing direction and support to telecom companies with regard to KM strategies. 


\section{References}

Aziz, B., Khan, T., \& Aziz, S. (2008). Impact of higher education on economic growth of Pakistan. Journal of Social Sciences and Humanities, 6(2), 15-29.

BBC. (1999, 14 October). Bridging the digital divide [Webpage]. Retrieved from

http://news.bbc.co.uk/2/hi/special_report/1999/10/99/inform ation_rich_information_poor/466651.stm.

Bigelow, M. (2002). How to achieve operational excellence. Quality Progress, 35(10), 70-75.

Bloodgood, J. M., \& Salisbury, W. D. (2001). Understanding the influence of organizational change strategies on information technology and knowledge management strategies. Decision Support Systems, 31(1), 55-69.

Bontis, N., \& Nikitopoulos, D. (2002). Thought leadership on intellectual capital. In N. Bontis (Ed.), World congress on intellectual capital readings (pp. 1-12). Boston, MA: Butterworth-Heinemann.

Budhwar, P. S., \& Debrah, Y. A. (Eds.). (2001). Human resource management in developing countries (pp. 104-105). London: Routledge.

Chase, R. L. (1997). The knowledge-based organization: An international survey. Journal of Knowledge Management, 1(1), 38-49.

Chong, S. C. (2006). KM critical success factors: A comparison of perceived importance versus implementation in Malaysian ICT companies. The Learning Organization, 13(3), 230-256.

Chosnek, J. (2010). Maintaining the corporate memory. Journal of Loss Prevention in the Process Industries, 23(6), 796-798.

De Long, D. W., \& Fahey, L. (2000). Diagnosing cultural barriers to knowledge management. Academy of Management Executive, 14(4), 113-127.

Demarest, M. (1997). Understanding knowledge management. Long Range Planning, 30(3), 374-384. 
Dieng, R., Corby, O., Giboin, A., Ribière, M., \& De Lucioles, R. (1999). Methods and tools for corporate knowledge management. International Journal of Human-Computer Studies, 51(3), 567-598.

Dransfield, R. (2000). Human resource management (pp. 68-70). Oxford: Heinemann.

Hibbard, J. (1997). Knowing what we know. InformationWeek, 20 October, pp. 46-64.

International Telecommunication Union. (2006, June 3). Liberalization of the telecom sector in Pakistan: An appraisal of the past two years [Webpage]. Retrieved from http://www.itu.int/ITU$\mathrm{D} /$ treg/newslog/Liberalisation+Of+The+Telecom+Sector+In+Pa kistan+An+Appraisal+Of+The+Past+Two+Years.aspx

Ives, W., Torrey, B., \& Gordon, C. (2002). Knowledge sharing is a human behavior. In D. Morey, M. Maybury, \& B. Thuraisingham (Eds.), Knowledge management: Classic and contemporary works (pp. 99-125). Cambridge, MA: MIT Press.

Johanson, U. (2005). A human resources perspective on intellectual capital. In B. Marr (Ed.), Perspectives on intellectual capital (pp. 96105). Oxford: Butterworth-Heinemann.

Klein, D. A. (1998). The strategic management of intellectual capital: An introduction. In D. A. Klein (Ed.), The strategic management of intellectual capital (pp. 1-7). Oxford: Butterworth-Heinemann.

Kosilov, A. (2008). KM self-assessment: A case study and the practical use of indicators. Trieste: School of Nuclear Knowledge Management.

Lank, E. (1997). Leveraging invisible assets: The human factor. Long Range Planning, 30(3), 406-412.

Luthy, D. H. (1998, August). Intellectual capital and its measurement. Paper presented at the 2nd Asia Pacific Interdisciplinary Research in Accounting Conference, Osaka, Japan.

Mårtensson, M. (2000). A critical review of knowledge management as a management tool. Journal of Knowledge Management, 4(3), 204-216. 
Massingham, P. (2008). Measuring the impact of knowledge loss: More than ripples on a pond? Management Learning, 39(5), 541-560.

McCall, C. H. (2001, November). An empirical examination of the Likert scale: Some assumptions, development, and cautions. Paper presented at the 80th Annual CERA Conference, South Lake Tahoe, CA.

Milton, N., Shadbolt, N., Cottam, H., \& Hamersley, M. (1999). Towards a knowledge technology for knowledge management. International Journal of Human-Computer Studies, 51(3), 615-641.

Muhammad, S. S., Aurangzeb, M, \& Tarique, I. (2009). Bridging the gap between higher education and the telecommunication engineering sector. US-China Education Review, 6(8), 62-67.

Natarajan, G., \& Shekhar, S. (2001). Knowledge management: Enabling business growth. Singapore: McGraw-Hill.

Pakistan, Ministry of Science and Technology. (2000). IT policy and action plan. Islamabad: Author.

Peters, D. M. (2007). Knowledge management: Four practical steps. In Managing knowledge to fuel growth (pp. 69-72). Cambridge, MA: Harvard Business School.

Petrash, G. (1996, October). Managing knowledge assets for value. Paper presented at the Knowledge-Based Leadership Conference, Boston, MA.

Prusak, L. (1996). The knowledge advantage. Planning Review, 24(2), 6-8.

Rana, T. M., Salaria, M. R., Herani, G. M., \& Amin, M. (2009). Identifying factors playing important role in the increasing employees' turnover rate: A case of telecom industry in Pakistan. Indus Journal of Management and Social Sciences, 3(2), 80-89.

Röller, L.-H., \& Waverman, L. (2001). Telecommunications infrastructure and economic development: A simultaneous approach. American Economic Review, 91(4), 909-923.

Saunders, R. M. (2007). Managing knowledge. In Managing knowledge to fuel growth (pp. 73-81). Cambridge, MA: Harvard Business School. 
Scalzo, N. J. (2006). Memory loss? Corporate knowledge and radical change. Journal of Business Strategy, 27(4), 60-69.

Sharp, C. A., \& Lewis, N. R. (1993). Information systems and corporate memory: Design for staff turnover. Australian Journal of Information Systems, 1(1), 75-83.

Sher, P. J., \& Lee, V. C. (2004). Information technology as a facilitator for enhancing dynamic capabilities through knowledge management. Information and Management, 41(8), 933-945.

Shoaib, M., Noor, A., Tirmizi, S. R., \& Bashir, S. (2009, November). Determinants of employee retention in telecom sector of Pakistan. Paper presented at the 2nd COMSATS International Business Research Conference, Lahore, Pakistan.

Smith, G. F. (1989). Defining managerial problems: A framework for prescriptive theorizing. Management Science, 35(8), 963-981.

Stewart, T. A. (1997). Intellectual capital: The new wealth of organizations. New York, NY: Currency/Doubleday.

Tiwana, A. (2002). The knowledge management toolkit: Orchestrating IT, strategy, and knowledge platforms (2nd ed.). New Delhi: Pearson.

van Heijst, G., van der Spek, R., \& Kruizinga, E. (1997). Corporate memories as a tool for knowledge management. Expert Systems With Applications, 13(1), 41-54.

Weiss, J. A. (1989). The powers of problem definition: The case of government paperwork. Policy Sciences, 22, 97-121.

Wiig, K. M. (1994). Knowledge management: The central management focus for intelligent-acting organizations. Arlington, TX: Schema Press.

Wiig, K. M. (1997). Knowledge management: Where did it come from and where will it go? Expert Systems With Applications, 13(1), 1-14.

Wilson, T. D. (2002). The nonsense of 'knowledge management'. Information Research, 8(1). Retrieved from http:/ / www.informationr.net/ir/8-1/paper144.html 
Whyte, W. H. (1957). The organization man. London: Jonathan Cape.

Zack, M. H. (1999). Knowledge and strategy. Boston, MA: ButterworthHeinemann.

Zajonc, R., \& Wolfe, D. (1966). Cognitive consequences of a person's position in a formal organization. Human Relations, 19(2), 139-150. 